\title{
Seduzir as massas: líderes populares e partidos políticos como dispositivos de controle das multidões
}

\author{
Seducing the masses: the popular leaders and \\ the political parties as crowd control devices \\ Amanda BRAGA \\ Universidade Federal da Paraíba (UFPB) \\ http://orcid.org/0000-0001-6026-5017
}

\begin{abstract}
RESUMO: O artigo tem por objetivo pensar a atuação dos líderes populares e dos partidos políticos como dispositivos de controle das multidões, operando abertura e fechamento das massas ao sabor das paixões políticas. Para tanto, parte-se das reflexões empreendidas por Foucault (1999), Le Bon (2018) e Courtine (2015) para discutir a emergência da multidão enquanto acontecimento histórico e objeto de pensamento no século XIX, bem como sua natureza e os modos de conduta disciplinares e biopolíticos que a governam. O intuito é considerar estes desenvolvimentos teóricos, que nos permitem compreender a espessura histórica constitutiva das massas, na análise de duas fotografias de Lula, uma de 1979 e outra de 2018, demonstrando o funcionamento dos dispositivos que estão lá materializados.
\end{abstract}

PALAVRAS-CHAVE: Dispositivo. Multidão. Líder popular.

ABSTRACT: The paper aims to analyze the performance of popular leaders and political parties as devices for the control of the multitude, operating the opening and closing of masses to the taste of political passions. To this end, it starts from the reflections of Foucault (1999), Le Bon (2018) and Courtine (2015), to discuss of the crowd emergence as a historical event and object of thought in the nineteenth century, as well as its nature and modes of disciplinary and biopolitical conduct that govern it. The aim is to consider these theoretical developments, which allow us to understand the historical thickness constituting the masses, in the analysis of two photographs of Lula, one from 1979 and the other from 2018, demonstrating the functioning of the devices that are materialized there.

KEYWORDS: Device. Multitude. Popular leader.

\section{Introdução}

Ao longo da década de 70 e ainda em parte da década de 80, Michel Foucault desenvolveu uma das problemáticas mais representativas de sua obra: aquela que liga os modos de objetivação dos sujeitos, tema geral de sua pesquisa, às distintas modalidades de poder que se deram a ver ao longo de sua análise da racionalidade política: i) o poder de soberania, cujo funcionamento delata uma primeira inserção dos processos naturais no interior do poder político, haja vista o direito de vida e de morte exercido pelo soberano sobre seus súditos: um poder que tem por função fazer morrer e deixar viver; ii) o poder disciplinar, que opera no nível da individualização dos corpos, 
agenciando seu treinamento, sua vigilância e, eventualmente, sua punição no interior das instituições disciplinares, no intuito de torná-los tanto mais úteis e produtivos quanto mais docilizados; iii) e o biopoder, que faz nascer a população como elemento político, científico e biológico, ocupando-se da regulação dos processos naturais comuns à multiplicidade dos homens: um poder que tem por função fazer viver e deixar morrer.

É precisamente a partir da articulação entre aquilo que Foucault (1999) entende como as duas acomodações dos mecanismos de poder - isto é, o poder disciplinar e o biopoder -, que este artigo coloca suas questões. O objetivo é relacionar a emergência das disciplinas no século XVII e da biopolítica ao final do século XVIII com a emergência da multidão enquanto acontecimento histórico e objeto de pensamento no século XIX, a fim de demonstrar o modo como se pode pensar, a partir daquele momento, a atuação dos líderes populares e dos partidos políticos na condição de dispositivos de controle das multidões, operando abertura e fechamento das massas ao sabor das intermitentes paixões políticas. Trata-se de uma proposta que decorre da intersecção entre: i) Foucault (1999), que pauta o exercício de um poder disciplinar e biopolítico, cuja atuação opera no nível do corpo e no nível da população, regulando tanto a individualidade quanto a multiplicidade das multidões; ii) Le Bon (2018), que formula, pela primeira vez, ao final do século XIX, os desenvolvimentos teóricos que permitem pensar a irrupção, a natureza e as formas de conduta das massas; iii) e Courtine (2015), cuja recente leitura da obra de Le Bon faz valer a dimensão histórica dos discursos sobre as multidões para a análise do campo político.

É considerando este panorama e no interior desta espessura histórica que este artigo propõe aplicar esta discussão a uma análise enunciativa. Conduz-se aqui a análise de dois enunciados - duas fotografias de Lula -, que flagram o funcionamento do líder popular e dos partidos políticos como modo de governo das massas: a princípio, com a irrupção de Lula, em 1979, e, na sequência, com o decreto de sua prisão, em 2018. O intuito é demonstrar que a própria dimensão história dos enunciados delata o funcionamento dos dispositivos que estão lá materializados. Para tanto, procederemos, a princípio, a uma rápida explanação do próprio conceito de dispositivo na obra de Michel Foucault, bem como seus desdobramentos disciplinares e biopolíticos para, na sequência, desenvolver a análise dos enunciados.

\section{Dispositivos de controle}


Conforme Agamben (2009, p. 27), dispositivo é "um termo técnico decisivo na estratégia do pensamento de Foucault", de modo que sua aplicação não prescinde de uma explanação, ainda que breve, acerca de seu aparecimento na obra do autor durante a primeira metade da década de 70. Tal aparição, segundo Agamben (2009), deve ser pensada à luz da noção de positivité, utilizada por Foucault durante a década de 60 - em A arqueologia do saber, por exemplo, publicada em 1969 -, da qual o dispositivo aproximar-se-ia não apenas etimologicamente, mas ainda naquilo que concerne a seu funcionamento.

É Jean Hyppolite, em ensaio intitulado Introduction à la philosophie de l'histoire de Hegel, que, na década de 40, analisa o termo positivité a partir da obra de Hegel, mais precisamente a partir do trabalho Die positivität der christliche religion (A positividade da religião cristã). Em seu ensaio, Hyppolite chama a atenção para a oposição proposta por Hegel entre religião natural e religião positiva: a primeira como relação direta e instintiva entre a razão humana e a instância divina, e a segunda, por seu turno, como normatização desta relação, no interior da qual os ritos seriam apresentados aos indivíduos coercitivamente, pressupondo, portanto, uma relação de comando e obediência. Para Agamben (2009), mais do que uma oposição entre as distintas formas de manifestações religiosas, essa leitura operada por Hyppolite mostra uma dialética entre liberdade e coerção ou entre razão e história: "Num certo sentido, a positividade é considerada por Hegel como um obstáculo à liberdade humana” (HYPPOLITE, 1983 apud AGAMBEN, 2009, p. 31).

É precisamente este funcionamento de uma positividade como instância repressiva, cuja atuação - por meio de regras, rituais e instituições - é naturalizada pelos indivíduos, que incita Agamben (2009) a fazer aproximar positividade e dispositivo. Se Michel Foucault não dedicou um texto exclusivamente a esclarecer esta última noção, a entrevista concedida por ocasião da publicação do primeiro volume da História da sexualidade, em 1977, pode ratificar a leitura de Agamben. Isto porque, ao ser interrogado sobre a natureza do dispositivo, sua composição e seu modo de funcionamento, Foucault responderá que, por esse termo, pretende demarcar:

em primeiro lugar, um conjunto decididamente heterogêneo que engloba discursos, instituições, organizações arquitetônicas, decisões regulamentares, leis, medidas administrativas, enunciados científicos, proposições filosóficas, morais, filantrópicas. Em suma, o dito e o não dito são os elementos do dispositivo. O dispositivo é a rede que se pode 
estabelecer entre estes elementos. Em segundo lugar, gostaria de demarcar a natureza da relação que pode existir entre estes elementos heterogêneos. Sendo assim, tal discurso pode aparecer como programa de uma instituição ou, ao contrário, como elemento que permite justificar e mascarar uma prática que permanece muda; pode ainda funcionar como reinterpretação desta prática, dando-lhe acesso a um novo campo de racionalidade. Em suma, entre estes elementos, discursivos ou não, existe um tipo de jogo, ou seja, mudanças de posição, modificações de funções, que também podem ser muito diferentes. Em terceiro lugar, entendo dispositivo como um tipo de formação que, em um determinado momento histórico, teve como função principal responder a uma urgência. O dispositivo tem, portanto, uma função estratégica dominante (FOUCAULT, 1979, p. 244).

Assim, em Foucault, o dispositivo compreende a rede estabelecida entre um conjunto de elementos discursivos e não-discursivos, a partir dos quais se estabelece um jogo que tem por finalidade responder a uma urgência, o que lhe confere, portanto, uma função estratégica. "Trata-se no caso de uma certa manipulação das relações de força, de uma intervenção racional e organizada nestas relações de força, seja para desenvolvê-las em determinada direção, seja para bloqueá-las, para estabilizá-las, utilizá-las, etc..." (FOUCAULT, 1979, p. 246). Tal ideia, segundo Agamben (2009), pode ser mapeada a partir de três pontos fundamentais: i) a natureza heterogênea dos elementos que compõem o dispositivo e a rede que se estabelece entre eles; ii) o exercício de uma função estratégica e sua inscrição em uma relação de poder; iii) uma composição abalizada pelo cruzamento das relações de poder com as relações de saber. Com isto, evidencia-se mais fortemente a vinculação da noção de dispositivo empreendida por Michel Foucault durante a década de 70 , e aquela de positivité utilizada durante a década de 60, por empréstimo à discussão de Hyppolite sobre Hegel:

\begin{abstract}
Se "positividade" é o nome que, segundo Hyppolite, o jovem Hegel dá ao elemento histórico, com toda sua carga de regras, ritos e instituições impostas ao indivíduos por um poder externo, mas que se torna, por assim dizer, internalizada nos sistemas de crenças e dos sentimentos, então Foucault, tomando emprestado este termo (que se tornará mais tarde "dispositivo"), toma posição em relação a um problema decisivo, que é também o seu problema mais próprio: a relação entre os indivíduos como seres viventes e o elemento histórico, entendendo com este termo o conjunto das instituições, dos processos de subjetivação e das regras em que se concretizam as relações de poder (AGAMBEN, 2009, p. 32).
\end{abstract}

Assim, em Hegel (ou pelo menos em sua leitura realizada por Hyppolite) como em Foucault, os termos positivité e dispositivo, respectivamente, estão postos na relação entre o indivíduo e a história. No primeiro, a positivité marca o modo como um conjunto de preceitos historicamente construídos são internalizados pelo indivíduo a partir da imposição de um poder externo. No segundo, o dispositivo agencia a relação 
dos indivíduos com uma rede de elementos que são, do mesmo modo, historicamente postos: as instituições, os processos de subjetivação, os mecanismos de poder. Não se trata, pois, de considerar o dispositivo, na obra de Foucault, como o exercício de uma tecnologia particular do poder. O dispositivo é, antes, um termo geral, que toma o lugar dos universais: "não simplesmente esta ou aquela medida de segurança, esta ou aquela tecnologia de poder, e nem mesmo uma maioria obtida por abstração: antes, como dizia na entrevista de 1977, 'a rede (le réseau) que se estabelece entre estes elementos"” (AGAMBEN, 2009, p. 33-34). É exatamente por este motivo - pelo lugar do universal que ocupa o dispositivo, pela sua natureza compósita, pelo seu exercício articulado a distintas formas de atuação -, que propomos pensar um dispositivo de controle que não esteja relacionado exclusivamente a uma ou a outra modalidade do poder, mas que esteja posto justamente na rede que se estabelece entre as diferentes tecnologias, mais precisamente entre o poder disciplinar e o biopoder.

Com isto, têm-se que pensar os dispositivos de controle impõe a compreensão da metodologia de atuação tanto das disciplinas quanto da biopolítica, o que nos é apresentado por Foucault (1999) como contraponto ao poder de soberania. Vejamos, ainda que rapidamente e para encerar este tópico, uma descrição de tais metodologias.

A discussão sobre disciplina e biopolítica tem início, em Foucault, com a teoria clássica da soberania, quando o filósofo descreve o sujeito imerso no interior de uma modalidade de poder centrada no soberano, o qual tinha como principal atributo o direito de vida e de morte sobre seus súditos. Numa primeira inserção dos processos naturais no interior do campo do poder político, o direito de estar vivo ou de estar morto traduzia-se unicamente como um efeito da vontade do soberano. Neste sentido, concebe-se uma modalidade de poder exercida de modo desequilibrado, que pende sempre para o lado da morte: é apenas porque o soberano pode matar que ele detém seu poder sobre a vida dos súditos. "É essencialmente um direito de espada", diz Foucault (1999, p. 287). O poder de soberania não diz respeito, portanto, a um poder que faz viver ou morrer, tampouco a um poder que deixa viver ou morrer. Trata-se de um poder que tem por função fazer morrer e deixar viver.

Considerando-se, entretanto, que, "à velha mecânica do poder de soberania escapavam muitas coisas, tanto por baixo quanto por cima, no nível do detalhe e no nível da massa" (FOUCAULT, 1999, p. 298), Foucault relata a emergência, a partir do século XVII e mais precisamente no início do século XVIII, daquilo que entende como uma primeira acomodação dos mecanismos do poder: aquela que, ocupada com o nível 
do detalhe, assegura a distribuição e a organização dos corpos em um campo de visibilidades, operando a vigilância, o treinamento e o aperfeiçoamento do corpo individual na medida em que o submete à docilidade imposta pelos dispositivos disciplinares: “em qualquer sociedade, o corpo está preso no interior de poderes muito apertados, que lhe impõem limitações, proibições ou obrigações”. (FOUCAULT, 2013, p. 132). Uma tecnologia de poder disciplinar, portanto, que objetiva o sujeito em corpo-espécie.

A esta atuação disciplinar, ainda no século XVIII, viria ainda agregar uma segunda acomodação dos mecanismos de poder, desta vez ocupada não com o corpo, mas com a vida dos homens: com o homem-espécie. Se, por um lado, o poder disciplinar converte a multiplicidade dos homens em corpos individuais a serem constantemente adestrados e eventualmente punidos, a nova modalidade de poder que vem integrar-se à disciplina, por seu turno, se dirige à multiplicidade dos homens "na medida em que ela forma, ao contrário, uma massa global, afetada por processos de conjunto que são próprios da vida, que são processos como o nascimento, a morte, a produção, a doença, etc" (FOUCAULT, 1999, p. 289). Trata-se daquilo que Foucault entenderá como sendo uma biopolítica da espécie humana e que governará o nível da população, assumindo a administração, juntamente com o poder disciplinar e via dispositivos de segurança, daquilo que escapava ao poder de soberania: o corpo e a massa. Fazendo emergir a população como problema político, científico e biológico, e ocupando-se da regulação e da longevidade dos homens, o biopoder inverterá a fórmula imposta pela soberania, que tem por função fazer morrer e deixar viver. A biopolítica consiste, ao contrário, em fazer viver e deixar morrer.

Com isto, têm-se que os dispositivos de controle - disciplinares, biopolíticos dos quais tratamos, agem concomitantemente entre o corpo e a vida, entre a docilização e a regulação, entre a individualidade e a multiplicidade. São dispositivos que se organizam entre relações de saber e relações de poder, a partir das quais empreendem um dado planejamento estratégico e promovem o agenciamento de sujeitos e práticas, ratificando sua finalidade coercitiva e sua propensão histórica. A seguir, no desenvolvimento das análises enunciativas, propomos mais bem demonstrar o funcionamento de tais dispositivos, desta vez aliada à dimensão histórica dos discursos sobre as multidões.

\section{Entre a disciplina e a biopolítica: a multidão}




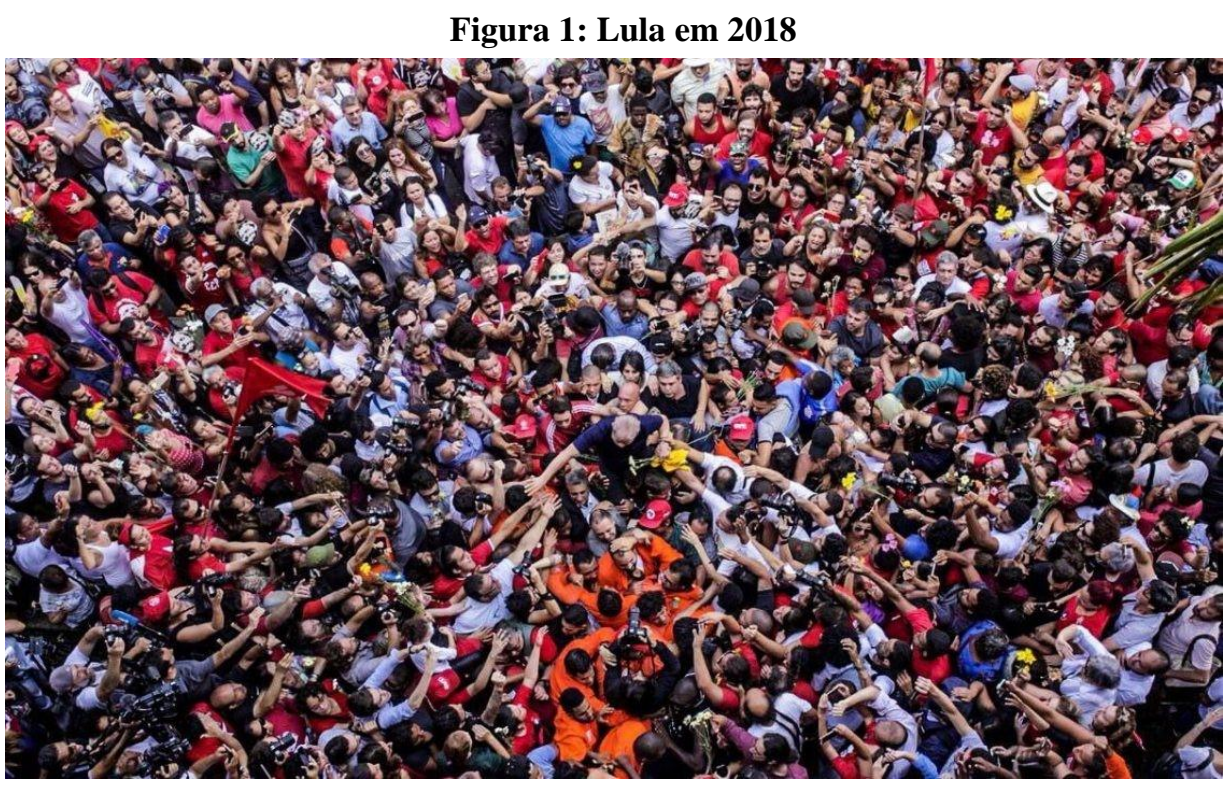

Fotografia: Francisco Proner

Em abril de 2018, após ter sido condenado em segunda instância e ter sua prisão decretada, Lula discursava em frente ao Sindicato dos Metalúrgicos do ABC, em São Bernardo do Campo. Este enunciado, uma fotografia, flagra o exato momento em que o ex-presidente desce do carro de som e é carregado por uma multidão de apoiadores até a sede do Sindicato, de onde sairia momentos depois para se entregar à Polícia Federal. Como se poderia prever, não apenas pela trajetória de Lula e do Partido dos Trabalhadores, bem como pela importância histórica do acontecimento, os momentos que antecederam a prisão de Lula foram transmitidos ao vivo em diversos meios de comunicação. Do material que produziu e divulgou a grande mídia, até aquele publicado nas redes sociais pelos eleitores do ex-presidente, passando por aquilo que produziram as mídias alternativas e, naturalmente, pela cobertura realizada pelo próprio Partido dos Trabalhadores, esta fotografia, sem dúvida, foi aquela que mais circulou, nacional e internacionalmente (ela aparece em jornais como The New York Times, The Guardin e El País, quando da notícia acerca da prisão de Lula). Considerada, posteriormente, como uma das imagens do ano de $2018^{1}$, a fotografia guarda sua força não apenas pela sua capacidade de narrar o ápice de uma histórica mobilização política e popular, mas

1 Disponível em: <https://pt.org.br/foto-do-abraco-a-lula-de-francisco-proner-e-escolhida-imagem-doano/>. Acesso em: 19 fev. 2019. 
também pela sua capacidade de fazer emergir a memória outras fotografias, produzidas quase 40 anos antes.

Figura 2: Lula em 1979

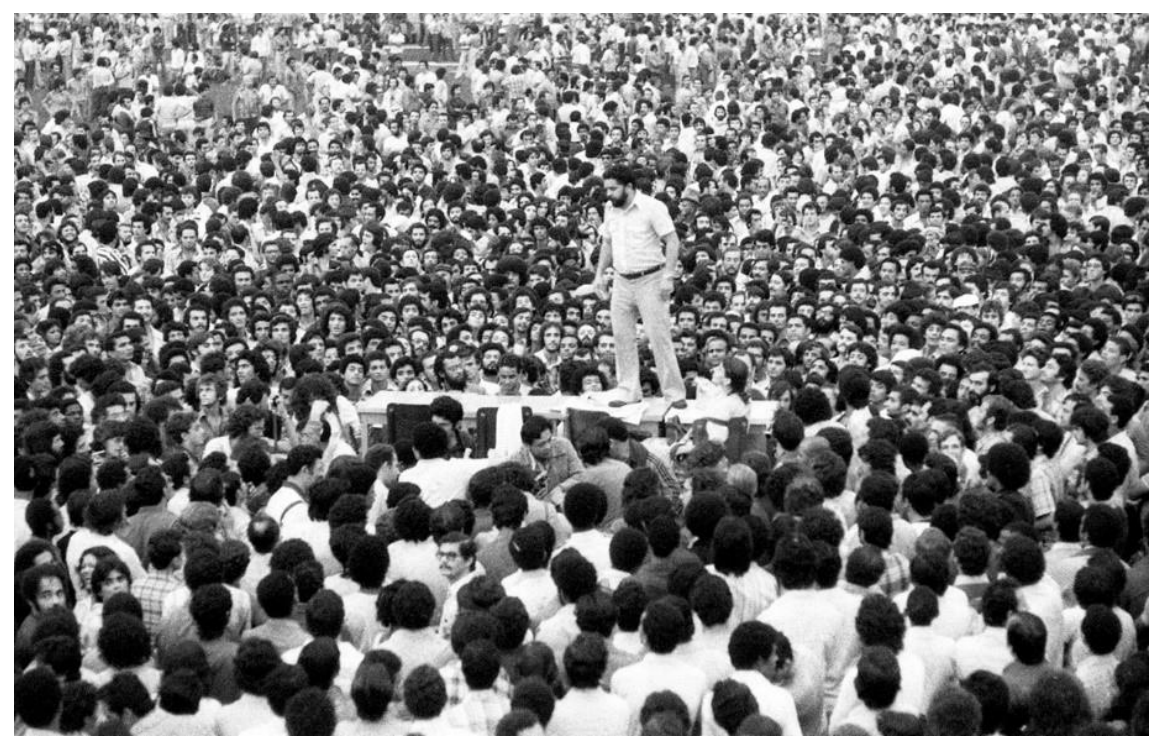

Fotografia: Fernando Pereira/ CPDoc JB

Em março de 1979, a mesma sede do Sindicato dos Metalúrgicos do ABC havia sido palco da primeira greve geral de uma categoria no país, desde a paralisação de Contagem (MG), em 1968: 200 mil metalúrgicos desafiavam a grande indústria automobilística da região e a repressão do governo militar. Diante da massiva adesão dos trabalhadores ao movimento, as assembleias deixaram de ser na sede do Sindicato para ser no Estádio Municipal Vila Euclides, cedido pelo então prefeito da cidade. Neste segundo enunciado, também uma fotografia, tão histórica quanto a primeira, em cima de uma mesa de escritório improvisada como palco, e sem qualquer sistema de som que pudesse amplificar e transmitir sua voz, Lula, cercado de trabalhadores, usava um megafone: aqueles que estavam mais próximos transmitiam suas palavras, em coro, aos que estavam mais afastados. Sessenta mil pessoas em um estádio esportivo fazendo ecoar aquilo que dizia o então sindicalista. A histórica greve geral dos metalúrgicos do ABC, em 1979, é um marco na história de Lula como líder popular, bem como na história do Partido dos Trabalhadores, que seria criado no ano seguinte.

Entre os dois enunciados ou, ainda, entre o ex-presidente condenado da primeira fotografia e o metalúrgico sindicalista da segunda, ambos cercados por uma imensa mobilização popular que os reconhece como líderes, há "um fio tênue, mas tenaz, que atravessa e tece a teia das palavras e das imagens" (COURTINE, 2013, p. 24). Esse fio é 
a própria história. Para analisá-lo, no intuito de fazer jus à espessura histórica dos enunciados aqui postos, propomos partir da discussão empreendida por Courtine (2015) sobre o final do século XIX e o início do século XX: é esse momento histórico que nos possibilita abordar a emergência dos discursos sobre a multidão, seu líder e seus dispositivos de controle, justamente porque é esse momento histórico que flagra o nascimento das grandes cidades e a emergência das sociedades de massa. É no século XIX que as grandes aglomerações humanas fariam emergir a multidão como acontecimento histórico e objeto de pensamento, acerca das quais seriam postas questões até então inéditas: como dominar o poder e a fúria das multidões, como convencê-las e guiá-las? Como, enfim, controlá-las? É o medo da multidão, ainda segundo Courtine (2015), que a torna um objeto de pensamento. É o medo ao mesmo tempo de sua inquietação e de sua potência, de sua capacidade de destruição. O medo da "força cega do número", manifestada "sob a forma da violência política e social das greves, do progresso dos movimentos trabalhistas e socialistas" (COURTINE, 2015, p. 265).

Retomando as obras de Gustave Le Bon (1896) e de Emile Zola (1968), Courtine (2015) mostrará que esse medo, característico da derrocada das antigas formas de autoridade e da emergência de uma força política advinda das multidões, é, em suma, o medo daquilo que se entendeu como sendo a natureza feminina das multidões: "lê-se 'a multidão' e entende-se 'a mulher'” (COURTINE, 2015, p. 267). Por este motivo, seu estado psicológico, à imagem do que seriam as emoções femininas, perpassaria sentimentos como "a impulsividade, a irritabilidade, a inconstância, os exageros e simplificações dos sentimentos, a credulidade", ou, ainda, a irracionalidade e a imprevisibilidade (COURTINE, 2015, p. 266), conjunto que Le Bon (2018), à luz do darwinismo social, afirmaria ser observável em seres inferiores da cadeia evolutiva.

Da sexuação posta nesta descrição da multidão, pelo menos duas propriedades decorrem. A primeira delas refere-se aos usos da voz e da fala pública pela multidão: "A multidão vocifera, protesta, geme ou delira - de raiva ou de prazer: a massa não fala" (COURTINE, 2015, p. 271). O povo, portanto, aglomerado sob a forma de multidão, coloca em xeque a estabilidade da clássica organização das cenas oratórias, nas quais o orador detém o poder da palavra diante de uma plateia silenciosa. A voz do povo não se situa nem no silêncio e nem tampouco na articulação da fala: sua expressão está, antes, em murmúrios e burburinhos coletivos, em gritos e palavrões, em explosões nervosas e inflamadas emoções. 
A segunda propriedade, por seu turno, refere-se à necessidade de um líder. Segundo Le Bon (2018, p. 111), "Nos grupos humanos, o líder possui um papel considerável. Sua vontade é o núcleo em torno do qual se formam e se identificam as opiniões. A multidão é um rebanho que não poderia prescindir de um mestre". As massas precisam, pois, de um guia. Mais que um simples guia: um líder carismático que não apenas seja oriundo da multidão, posto que "a voz do povo emerge do corpo do povo" (COURTINE, 2015, p. 281), mas que também fale em seu nome e a seu modo. Tomada de fascinação pelo líder, a massa se dobra: "sua coragem a seduz, sua autoridade se impõe sobre ela e sua espada a amedronta" (LE BON, 1896 apud COURTINE, 2015, p. 283).

O líder eleito trabalhará, enfim, em prol do fechamento das massas, em uma contenção daquilo que parecia ingovernável, uma gestão das grandes populações. Tal fechamento seria visível não apenas na eleição e no reconhecimento do líder, mas também mediante a criação e a consolidação de organizações políticas (partidos, sindicatos, associações), de modo que tanto um quanto outro (tanto o líder quanto as organizações) passariam a funcionar enquanto dispositivos de controle das multidões.

A princípio, pode-se pensar líder popular e organizações políticas como dispositivos de controle disciplinares, pensando as disciplinas justamente como "métodos que permitem o controle minucioso das operações do corpo, que realizam a sujeição constante de suas forças e lhes impõem uma relação de docilidade-utilidade", conforme Foucault (2013, p. 133). Assim, líder popular e organizações políticas seriam dispositivos cujas finalidades estariam ligadas a uma certa ordenação da multiplicidade que compõe a multidão, garantindo a organização espacial dos corpos, sua separação, seu alinhamento, e assegurando sua docilização pelo aumento de sua força útil, na tentativa de atenuar o terror das revoltas, dos complôs, da desordem, da dispersão e da instabilidade constitutiva das massas. Não por acaso, Foucault afirmará que a política pode ser concebida como a continuação do modelo militar, de modo a prevenir o distúrbio civil. "A política, como técnica da paz e da ordem internas, procurou pôr em funcionamento o dispositivo do exército perfeito, da massa disciplinada, da tropa dócil e útil" (FOUCAULT, 2013, p. 162). Trata-se, enfim, de uma disciplinarização individualizada dos corpos que compõem a multidão e, portanto, de seu fechamento, na medida em que cada indivíduo reconhece sua demanda e sua voz na coesão singular de um líder ou na postura proposta por um partido político, por 
exemplo, abrindo mão, por consequência, de uma atuação "explosiva", instável e, portanto, perigosa junto à massa.

Pode-se pensar, do mesmo modo, líder popular e organizações políticas como dispositivos de segurança no interior de um Estado biopolítico, preocupado com a operacionalização de uma dada governamentalidade como técnica de governo dos vivos, pensados aqui não mais como corpos a serem disciplinados, mas como população a ser normalizada: passagem do homem-corpo para o homem-espécie. Trata-se, nas palavras de Foucault (1999, p. 289), de uma tecnologia que "se dirige à multiplicidade dos homens, não na medida em que eles se resumem em corpos, mas na medida em que ela forma, ao contrário, uma massa global, afetada por processos de conjunto que são próprios da vida, que são processos como o nascimento, a morte, a produção, a doença, etc.” (1999, p. 289). Nesse cenário, a fim de atuar na garantia desta normalização social, líder e partido trabalhariam na condição de instrumentos técnicos na produção de análises, cálculos e reflexões sobre as necessidades da população: é preciso regular a produção, a circulação e o consumo de alimentos, é preciso prevenir as doenças, é preciso criar instituições de assistência, é preciso garantir, enfim, a longevidade dos cidadãos, é preciso fazê-los viver (FOUCAULT, 2008).

Dispositivos disciplinares de um lado e dispositivos de segurança do outro, no entanto, longe de atuarem de modo isolado, atuam de forma articulada e concomitante. Com o nascimento das grandes cidades e a emergência das sociedades de massa entre os séculos XIX e XX, é possível flagrar a problemática das cidades e das multidões enredada entre a disciplina e a segurança: a princípio, a disposição espacial dos corpos no espaço (as casas, as quadras, o recorte das ruas) nos diz algo sobre a visibilidade dos indivíduos e a disciplinarização de seus comportamentos individuais; do mesmo modo, a regulação do sistema financeiro que permite a aquisição dessas habitações, a circulação das mercadorias, as regras de recolhimento do lixo, nos diz algo sobre a normalização da vida da população como um todo. De uma forma ou de outra, a problemática das cidades de que fala Foucault (1999) está posta no exato momento em que está posta a problemática das multidões de que fala Le Bon (2018), justamente porque é preciso impedir que as massas se tornem um problema de circulação urbana e gatilho de toda desordem. Nesse sentido, é necessário condensar a multidão nas cidades, organizá-la, discipliná-la, torná-la útil, mas também longeva, é necessário evitar as aglomerações que possam, porventura, afrontar a ordem pública: um fértil terreno, portanto, para apresentação dos dispositivos de controle capazes de garantir sua 
docilidade. Trata-se daquilo que Courtine (2015), retomando Canetti (1995), entenderá como sendo "a conversão das massas abertas em massas fechadas", o que implicaria dizer que as massas passariam a dispor de um piso e de um teto: "uma vez que sua forma é a de um líquido contido em um recipiente, é necessário um constante e rigoroso controle para que elas não transbordem" (COURTINE, 2015, p. 277).

Se voltamos, agora, aos enunciados apresentados incialmente, é possível promover uma leitura que leva em conta não apenas a emergência da multidão enquanto objeto de pensamento, mas também o nascimento, nesse cenário, dos líderes populares, bem como a necessidade de contenção das massas via dispositivos de controle. Assim, o enunciado em que está retratado o Lula sindicalista, produzido no auge da greve dos metalúrgicos, em 1979, flagra mais do que o pronunciamento do então metalúrgico em um estádio esportivo. O enunciado flagra a aglomeração de uma multidão que estava, até ali, dispersa sob a forma de minorias em greve, flagra a atuação do sindicato na condição de dispositivo de controle, que agencia e convoca uma multidão para promover seu fechamento em torno de um líder. O enunciado flagra, além disso e principalmente, o nascimento de seu líder, o qual, assim como o previu Le Bon (2018), não apenas emergiu da própria multidão como também, em seu corpo, carrega os traços do trabalho manual do operário. Como evidência, basta que atentemos à própria materialidade enunciativa: Lula, ao centro, demonstra a sedução e a autoridade esperada de um líder, haja vista a própria multidão que o rodeia e espera por seus encaminhamentos. A própria disposição dos grevistas na fotografia o comprova: aqueles que aparecem no canto inferior estão de costas ao leitor; aqueles que estão no canto superior encontram-se de frente. Todos, enfim, olham para o centro, seduzidos pelo guia. Além disso, não se vislumbra, aqui, a assepsia esperada do cenário político. Ao contrário disso, seus gestos corporais, sua roupa informal, sua barba, seus cabelos ressoam a rusticidade do trabalho operário. O que este enunciado flagra, enfim, é um recorte da história política brasileira diante de uma sociedade de massa e, ao mesmo tempo, o fechamento dessa massa mediante a atuação de seus dispositivos de controle: o Sindicato dos Metalúrgicos, um líder popular inegavelmente carismático e representativo de seu grupo e, certamente, o Partido dos Trabalhadores, que seria criado no ano seguinte.

O enunciado que retrata o Lula ex-presidente, por sua vez, quase 40 anos além, flagra o retorno das multidões às ruas, justamente porque o controle exercido pelos dispositivos aqui sugeridos (o líder popular, os partidos políticos, os sindicatos) 
trabalham não apenas no fechamento das massas mediante sua contenção, mas também mediante sua abertura, quando assim é necessário. Retrata-se, aqui, não mais a escolha de seu líder, mas a incitação da multidão à retomada de seu reconhecimento enquanto tal. Por um lado, bem como na fotografia anterior, ainda que a imagem tenha sido produzida em outro ângulo, a organização dos indivíduos se dá de modo análogo: uma imensa multidão em torno de Lula, ao centro da imagem. Para além das tantas cabeças, os braços estendidos em direção ao ex-presidente, numa tentativa última de tocá-lo, ratificam a consolidação não apenas de seu poder de sedução enquanto líder, mas também de sua história junto às massas: "um estado de sujeição e fascinação amorosa, numa relação hipnótica com o líder", como diria Freud (apud COURTINE, 2015, p. 268). E isto num momento político em que se agrava, paradoxalmente e a passos largos, uma crise de representatividades políticas. Por outro lado, ao contrário da fotografia anterior, em que Lula estava em cima de uma mesa, aqui, o ex-presidente está, literalmente, nos braços do povo, mistura-se e confunde-se com ele, num apagamento dos limites e das distâncias que os distinguem e os separam, já que agora, mais do que nunca, é preciso ratificar sua origem. Não por acaso, um dos enunciados utilizados pelo Partido dos Trabalhadores para divulgar trechos das entrevistas concedidas por Lula foi: Fala, Lula. Ninguém cala a voz povo, de modo a sugerir que a voz de Lula é a voz do povo e que, portanto, Lula é o povo, o que reforça nossa tese de sua atuação como dispositivo de controle de fechamento e/ou de abertura das multidões, ao sabor das paixões políticas.

\section{Considerações finais}

Para encerrar a discussão aqui empreendida, ressaltamos ainda que essa problematização sobre a multidão, seus guias e seus dispositivos de controle não parte do pressuposto de uma multidão compactada em uma massa homogênea e alheia às resistências intrínsecas às relações de poder e à constituição das subjetividades, mas de uma "pluralidade composta de diferenças internas", embora agencie, ainda assim, "uma gramática comum capaz de instituir horizontes coletivos de reunião e deliberação sobre a gestão do espaço e dos recursos disponíveis", conforme Narita (2019, p. 91-92). A multidão seria, neste sentido, "um projeto de organização política da multiplicidade" (NARITA, 2019, p. 94). 
Além disso, se pensamos especificamente no cenário político brasileiro, é também preciso observar o pretenso paradoxo que se instala quando observamos, por um lado, a manutenção do funcionamento dos líderes populares e das organizações políticas como dispositivos de controle das multidões e, por outro, a grave crise de representatividade que nos solapa. Se países como a França ensaiam oferecer uma certa inflexão a esta manutenção, com a atuação dos coletes amarelos (les gilets jaunes), por exemplo, que tomaram conta das ruas do país em 2018 e se apresentam como movimento de "origem espontânea", desligado de qualquer partido ou liderança mais visível (embora isto se possa contestar); no Brasil, esses dispositivos não cessam de se fortalecer.

Basta que pensemos no poder de mobilização do MBL - Movimento Brasil Livre - ou da CUT - Central Única dos Trabalhadores - favorável e contrariamente, respectivamente, ao impeachment de Dilma, em 2016. Basta que pensemos no recente papel da UNE - União Nacional dos Estudantes - na defesa das universidades quando dos ataques por parte do Ministério da Educação. Basta que pensemos no papel de Jair Bolsonaro à frente das manifestações antidemocráticas, angariando apoio para um discurso que colocaria em xeque o próprio cargo que ocupa. Basta que pensemos na força de Lula no atual cenário político, mesmo quando preso e agora ainda mais porque livre, na continuidade de sua sedução como líder popular que arrasta multidões. Basta que pensemos, enfim, naquilo que recentemente afirmou Leonardo Boff, ao dizer que $o$ medo que se tem de Lula é o medo que se tem do povo ${ }^{2}$, de onde se poderia depreender que o medo que se tem de Lula é o medo que se tem da multidão que o rodeia. $\mathrm{O}$ medo que se tem de Lula é o medo que se tem, enfim, das efusivas paixões manifestadas por aqueles que o cercam.

\section{Referências}

AGAMBEN, Giorgio. O que é o contemporâneo? e outros ensaios. Trad. Vinicius Nicastro Honesko. Chapecó: Argos, 2009.

CANETTI, Elias. Massa e poder. Trad. Sergio Tellaroli. São Paulo: Companhia das Letras, 1995.

COURTINE, Jean Jacques. Decifrar o corpo: pensar com Foucault. Trad. Francisco Morás. Petrópolis: Vozes, 2013.

\footnotetext{
${ }^{2}$ Referência à postagem realizada por Leonardo Boff no Twitter em 03 de março de 2019: "Um homem com o coração partido, desarmado, é esperado por um soldado com fuzil. O medo que se tem do Lula é o medo que se tem do povo".
} 
COURTINE, Jean Jacques. A voz do povo: a fala pública, a multidão e as emoções na aurora da era das massas. In: COURTINE, Jean Jacques; PIOVEZANI, Carlos. (Org.). História da fala pública: uma arqueologia dos poderes do discurso. Petrópolis: Vozes, 2015. p. 261-289.

FOUCAULT, Michel. Sobre a história da sexualidade. In: FOUCAULT, Michel. Microfísica do poder. Trad. Roberto Machado. 22. ed. Rio de Janeiro: Graal, 1979. p. 243-276.

FOUCAULT, Michel. Em defesa da sociedade: curso no Collège de France (19751976). Trad. de Maria Ermantina Galvão. São Paulo: Martins Fontes, 1999.

FOUCAULT, Michel. Segurança, território e população: curso dado no Collège de France (1977-1978). São Paulo: Martins Fontes, 2008.

FOUCAULT, Michel. Vigiar e punir: nascimento da prisão. Trad. Raquel Ramalhete. 41. ed. Petrópolis: Vozes, 2013.

LE BON, Gustave. La psycologie des foules. Paris: Alcan, 1896.

LE BON, Gustave. Psicologia das multidões. Trad. Mariana Sérvulo da Cunha. 3. ed. São Paulo: Martins Fontes, 2018.

NARITA, Felipe Ivoti. Espectros da multidão. Revista USP, São Paulo, n. 122, p. 8998, jul./set., 2019.

ZOLA, Emile. Germinal. Paris: Garnier/ Flammarion, 1968. 